\title{
A longitudinal study of sexuality and gynecologic health in abused women
}

\author{
J. DUDLEY CHAPMAN, DO, PhD
}

Although the nature of the sexual dysfunctions that result from rape and abuse may vary, the study reported here suggests that the dysfunctions become chronic. Sexually violent assaults alter a woman's affective as well as her gynecologic and physiologic life. The author determined the frequency of sexual dysfunction in 100 women: 30 rape victims, 35 abuse victims, and 30 case-matched controls. The sexual inventory evaluated for sexual fears, sexual desire, sexual arousal, and orgasm. To evaluate the impact of the abuse on the gynecologic health of the victims, the gynecologic examination and interview focused on pain, dyspareunia, vaginismus, dysfunctional uterine bleeding, vaginitis, and pelvic surgery. Over a period of two to four years after the violent event, $61 \%$ of the raped and abused women had some sexual dysfunction. Almost the same percentage had gynecologic problems.

Studies of this nature are difficult because the victims are reluctant to participate and resistant to cooperate. Only $\mathbf{4 5} \%$ of the victims in the rape-crisis centers were willing to cooperate, while only $25 \%$ of those in the shelter for abused women were willing to provide a sexual history and consent to an interview and pelvic examination. Such factors need to be kept in mind when interpreting the data.

In recent years, the abuse of women and children has become a focus of increased concern. This is evident from the proliferation of published data. $^{1-8}$ Many of these studies suffer from methodological flaws, such as small subject sam- ples, lack of matched controls, and lack of objective criteria. Never reported is the number of abused women who refuse to engage in any form of study, with the typical justification that "I have been a victim, and research will make me more of a victim." This inherent skewing of the data has been mentioned by me in previous reports. ${ }^{9}$

In a survey of 83 victims of sexual assault, Becker and associates ${ }^{6}$ noted that $56 \%$ of the victims experienced sexual dysfunction post assault and that $71 \%$ of these felt that the assault had precipitated the dysfunction. Bart ${ }^{10}$ reported that $33 \%$ of the rape victims in his study experienced sexual problems post assault. McGuire and associates ${ }^{11}$ reported that a common finding in studies of abused women who are seeking management of sexual dysfunction is sexual molestation in childhood. In a longitudinal study of 81 adult rape victims, Burgess and Holmstrom ${ }^{12}$ noted that at six years post assault, $71 \%$ of the women reported decreased sexual activity subsequent to the assault. FeldmanSummers and colleagues ${ }^{13}$ also noted a decrease in sexual satisfaction following rape.

Becker and associates ${ }^{6-8}$ are the only investigators to include some physical symptoms in the sexual conduct constellation they discussed in all three of the reports reviewed. Their sexual dysfunction data included dyspareunia and vaginismus as well as such elements as fear of sex, desire disorders, arousal problems, and orgasmic difficulties. A review of the literature has revealed no previous study of abused women in which physical factors such as generalized pelvic pain, dysmenorrhea, gynecologic surgery, and abnormal uterine bleeding were considered.

\section{Purpose}

The purpose of this study was to (1) determine the frequency of sexual dysfunction in female rape vic- 


\begin{tabular}{|c|c|c|c|c|}
\hline \multicolumn{5}{|c|}{$\begin{array}{c}\text { Table } 1 \\
\text { Summary of Study Population Characteristics }(N=100)\end{array}$} \\
\hline \multirow[b]{2}{*}{ Population characteristics } & \multirow[b]{2}{*}{ No. } & \multirow[b]{2}{*}{$(\%)$} & \multicolumn{2}{|c|}{ Age (yr) } \\
\hline & & & Range & Mean \\
\hline \multicolumn{5}{|l|}{ Population and history } \\
\hline From rape crisis centers & $\begin{array}{l}30 \\
28\end{array}$ & (93) & $11-81$ & 20 \\
\hline Private practice patients & 2 & $(7)$ & & \\
\hline \multicolumn{5}{|l|}{ Rape history } \\
\hline - No prior assault & 16 & (53) & & \\
\hline -Prior assault & 14 & (47) & & \\
\hline \multirow{2}{*}{\multicolumn{5}{|c|}{$\begin{array}{l}\text { by "significant other" (friend, } \\
\text { date, mate) } \\
\text { by family member }\end{array}$}} \\
\hline by family member & 5 & $(36)$ & & \\
\hline \multicolumn{5}{|l|}{ - Group 2 (abuse victims) } \\
\hline From local shelter & 30 & $(85)$ & $19-55$ & 25 \\
\hline Private practice patients & 5 & (15) & & \\
\hline \multicolumn{5}{|l|}{ Abuse history } \\
\hline -No prior abuse & 5 & (15) & & \\
\hline -Prior abuse & 30 & (85) & & \\
\hline \multicolumn{5}{|l|}{ Race (both groups) } \\
\hline White & 52 & $(80)$ & & \\
\hline Black & 5 & $(7)$ & & \\
\hline Hispanic & 8 & (13) & & \\
\hline \multicolumn{5}{|l|}{ - Group 3 (case controlled* from } \\
\hline private practice) & 35 & & & \\
\hline
\end{tabular}

tims, abused women, and a case-controlled matched study group and (2) evaluate the impact of the abuse on the gynecologic health of the victims.

\section{Methodology \\ Population}

The study population consisted of a total of 100 subjects, comprising three study groups. Group 1 consisted of 30 women: 28 were from two area rapecrisis centers, and 2 were assault victims from my private practice who had heard about the study and requested to participate. Group 2 consisted of 30 women from one local shelter for abused women and 5 patients from my private gynecologic practice. Group 3, the control group, consisted of 35 women from my private gynecologic medical practice who were matched with the subjects in the study groups by age, education, religious practice or background, marital status, and parity and who denied any experience of abuse or rape.

Attempts to gain the cooperation of the victims in the rape crisis centers and the shelter for abused women were met with great resistance. A similar resistance was encountered in an earlier study on gynecologic surgery, in which only $71 \%$ of the sub- jects agreed to provide a sexual history. ${ }^{9}$ From March 1986 to November 1987, all women who sought help at the rape crisis centers and the shelter were asked to participate in this study. In the rape-crisis group, $45 \%$ were willing to participate; in the shelter-for-abused women group, only $25 \%$ were willing to provide anyone with a sexual history and gynecologic follow-up. This resistance to participate can easily be a source of self-selection bias, which must be kept in mind when interpreting the data.

For the purposes of this study, rape (assault) is defined as genital violation; abuse is defined as physical or mental injury or both (home-centered/ by the husband or a lover). For group 1, the age ranged from 11 to 81 years, with a mean age of 25 and a median age of 20 . For group 2, the age range was from 19 to 55 years, with both a mean age and a median age of 25 . The racial mix, consistent for both groups, was $80 \%$ white, $13 \%$ Hispanic, and $7 \%$ black.

Of the rape victims, 16 (53\%) had never been previously assaulted or abused, while $14(47 \%)$ had been previously abused. Of the shelter group, 30 women $(85 \%)$ admitted to prior abuse, while 5 $(15 \%)$ denied it. For the subjects in group 1, the 
prior abuser could be identified as an ex-family member in $36 \%$ of the cases and as a "significant other," such as a friend, date, or mate, in $22 \%$. For those in group 2 , the abuser was almost exclusively a significant other. The women in the control group were screened for a history of prior rape or abuse. Table 1 summarizes the population characteristics. Student's $t$-test and an analysis of variance, ANOVA, were used to evaluate the data. A $P$ value of .05 was used as the critical value for statistical significance.

\section{Definitions}

Desire disorder: The desire phase refers to the time during which an individual feels a need for sexual contact, a need for intimacy or for physical release via the physical genital apparatus. A desire disorder is therefore any alteration or lack of this need. Arousal dysfunction: This phase of the sexual response cycle (a parasympathetic manifestation) is characterized by vaginal lubrication and increasing desire associated with enhanced myotonia and vasocongestive changes within the pelvis. Arousal dysfunction then is any change, interruption, or alteration of this physiology.

Orgasm: This is the aspect of the sexual response cycle that is mediated through the sympathetic branch of the autonomic nervous system and characterized by intense vaginal lubrication, myotonia, and altered consciousness. It is a release of the physiologic sexual tension that has built up.

\section{Procedure}

In the geographic area in this study, people in distress can telephone the personal helpline or the sexual assault line for assistance. These countywide, toll-free numbers are staffed by trained laypersons who listen, advise, and direct callers to appropriate care facilities. Rape victims are advised to seek immediate attention at local hospital emergency rooms, and abused women are directed to the shelter for abused women. Except for the seven patients who were under my private care, the subjects of this study had been referred to the care facilities.

After the acute situation had been attended to, all the women were asked if they would participate in a sexual and gynecologic evaluation that would be repeated every six months over a fouryear period. During each evaluation, data were recorded for all the standard items in the sexual and gynecologic inventories. The control group participants likewise were evaluated every six months over a four-year period. This standard procedure is one any conscientious gynecologist would/should do during a patient interview. Informed consent was obtained from all participants.

The sexual inventory was constructed to include sexual fears, sexual desire, sexual arousal, and orgasm. The gynecologic review was constructed to examine dysmenorrhea, pelvic pain, dyspareunia, vaginismus, dysfunctional uterine bleeding, vaginitis, and pelvic surgery. The cases were reviewed individually, within the specific group, (assaulted, abused, control). The prospective subjects were screened so as to eliminate any woman who admitted to having had gynecologic or sexual difficulties (or both) prior to her first episode of abuse/rape.

\section{Results}

The analysis of the data is presented according to sexual dysfunction to conform with the format used in the previously cited literature. The sexual issues that form the outline of the discussion will be evaluated to study any relationship to gynecologic problems.

The analysis of the data revealed that $61 \%$ of the women in groups 1 and 2 had some sexual dysfunction and that almost the same percentage had gynecologic problems. For group 3, the rate for sexual dysfunctions and gynecologic problems was $31 \%$, which is comparable to the percentages given in the standard texts (eg, Kistner's ${ }^{14}$ and Masters and Johnson's ${ }^{15}$ ).

\section{Fear of sex}

On a nonspecific inquiry, most women will express some apprehension about sex, and most will attribute their apprehension to their being the recepteewhether the sex is vaginal, oral, or anal. In this study, however, only $5 \%$ of the control group expressed a fear of sex, while $60 \%$ of the rape victims and $48 \%$ of the abuse victims listed fear as a factor. In rape victims, the fear was almost paralyzing, yet they did not show a higher incidence of gynecologic symptoms or surgery than did the women in the control group $(P>.05)$.

\section{Desire disorder}

Almost all women periodically experience a reactionary indifference to sex, but for the women in the true desire-disorder group, this indifference is a slowly increasing phenomenon. In the control group, about one third of the women felt a lack of desire from time to time; but only $7 \%$ reported a constant lack of desire, and this appeared to be caused by the behavior of the partner. That is, the partner was always asking or demanding while 


\begin{tabular}{|lccc|}
\hline \multicolumn{4}{c|}{$\begin{array}{c}\text { Table 2 } \\
\text { Summary of Results }\end{array}$} \\
\hline Results & \multicolumn{3}{c|}{ Victims (\%) } \\
\cline { 3 - 4 } & Control (\%) & Rape & Abuse \\
\hline - Sexual difficulties & 31 & & 61 \\
- Sexual parameters & & & \\
Fear & 5 & 60 & 48 \\
Desire & 7 & 65 & 55 \\
Arousal & 9 & 60 & 40 \\
Orgasm & 30 & $\ldots$ & $\ldots$ \\
- Occasionally & 15 & $\ldots$ & $\ldots$ \\
- Always & $\ldots$ & 70 & 60 \\
- Fail & & & \\
\hline
\end{tabular}

never permitting the woman to find out or to satisfy her own sexual needs or desires.

In group 1, however, $65 \%$ of the women reported a sexual desire disorder; and in group 2, 55\%. In almost all of the women in groups 1 and 2, the lack of desire had been almost total immediately following the act of victimization and then had decreased over the next six months. For the victims who developed a true disorder, the lack of desire slowly became more pronounced over the first two years after the event. Between the second and fourth years following the event, these women suffered an increase in an ill-defined noncyclical pelvic pain pattern $(P<.01)$. In comparison with the control group, no other significant gynecologic patterns were noted.

\section{Arousal dysfunction}

For the control group, about $20 \%$ of the women reported periods of slow arousal that varied with the stresses of daily living and with changes in their interpersonal relationships. These arousal difficulties were variable and short-lived and were of no real concern to the women. Only $9 \%$ of group 3 reported ongoing arousal difficulties. For group 1, $60 \%$ of the women reported arousal problems and for group 2, 40\%. Most often this difficulty was described as "not being able to get with it" or "being very dry, and it made it hurt a lot." Many attributed their problem to the penis size of their regular partner, while others said they thought something was wrong.

For groups 1 and 2, after victimization the women reported a threefold increase (significant at $P<.05$ ) in pelvic pain and gynecologic surgery, which ranged from curettage to laparoscopy to hysterectomy. Four percent of the women had vaginismus and $10 \%$ had dyspareunia. Vaginismus al-
Table 3

Summary of Results, Continued

\begin{tabular}{|lc|}
\hline $\begin{array}{c}\text { Sexual } \\
\text { parameters } \\
\text { (disorder) }\end{array}$ & Gynecologic patterns \\
\hline Fear & $\begin{array}{c}\text { No change in control or study } \\
\text { group }(P=.01)\end{array}$ \\
Desire & $\begin{array}{c}\text { Only noncyclic pain and surgery in } \\
\text { study group }(P=.05)\end{array}$ \\
Arousal & $\begin{array}{c}\text { Threefold increase in pain and surgery } \\
\text { in study group }(P=.05)\end{array}$ \\
& $\begin{array}{c}\text { Fourfold increase in pain, dysmenor- } \\
\text { rhea, or dyspareunia in study group }\end{array}$ \\
& $\begin{array}{c}\text { Fivefold increase in hysterectomy in } \\
\text { study group }(P=.05)\end{array}$ \\
& $\begin{array}{c}10 \% \text { had dyspareunia in study group; no } \\
\text { statistical difference in control group }\end{array}$ \\
& $\begin{array}{c}10 \% \text { had vaginismus in study group; no } \\
\text { statistical difference in control group }\end{array}$ \\
\hline
\end{tabular}

most always stems from a psychologic phenomenon; however, in $50 \%$ of the cases, dyspareunia appears as a secondary effect of a psychologic event or is otherwise considered to be of gynecologic origin. Almost all the anorgasmia was what is defined as secondary: these women could or did have orgasms but not with the penis in the vagina; and after the victimization, the entire constellation worsened with time.

\section{Orgasm}

In The Hite Report, ${ }^{16}$ Shere Hite writes that only one third of the women in her study had ever had an orgasm with the penis in the vagina. In this study, $15 \%$ of the women in the control group reported having an orgasm in all sexual engagements; for the group as a whole, the women reported having an orgasm in or during coitus $30 \%$ of the time. In contrast, fully $70 \%$ of the women in group 1 had difficulty achieving or experiencing orgasm, and $60 \%$ of those in group 2 found orgasm unattainable or elusive. In fact, these group 2 women did not have an orgasm of any kind nor did they make the common statement to the effect that "I was almost there, but I just couldn't get it." Their sexual response was weaker than that of the typical woman with orgasmic difficulties, whose problem often results from her "trying too hard." The "trying too hard" causes sympa- 
thicotonia to intervene in the parasympathetic element of the sexual response cycle and prevent the total conversion that characterizes orgasm. ${ }^{17}$ The average woman with orgasmic difficulty can "see/ feel" the fringe of orgasm; abused/raped women cannot get even that far down the route of the autonomic nervous system. They are more "numb." Tables 2 and 3 summarize the results.

\section{Illustrative cases}

\section{Case 1}

This subject is a 36-year-old divorced white woman: At age 17 she had moved away from home in search of independence, and four to six weeks later she was raped in her apartment by an unknown intruder. She was emotionally stunned by this event, but she received little or no support from the legal system, social agencies, or her family. She kept very quiet about this trauma, and at age 20 she married a man who, for the most part, ignored her sexually. Her sex life was characterized by fear, lack of desire, and lack of arousal. Shortly after the birth of their only child, her husband left her. After his abandonment, she engaged in sexual activities with a large number of men. These experiences left her still more confused and without a better understanding of the reasons for her failure to become aroused or to achieve orgasm.

Later she was date raped and subsequently had even more partners. She consulted a physician for postcoital pain, and a curettage and laparoscopy were performed. No gross pathology was evident. Later she had a second laparoscopy for sterilization, and again no abnormalities were noted. In her pursuit of understanding of her sexual being, she continued to have intercourse with many men and to experience increasing pain. She married a second time, and this husband, too, proved to be sexually indifferent.

During the relationship, she became severely depressed, and her physical health also deteriorated. Her condition eventually resulted in a hysterectomy with bilateral salpingo-oophorectomy, after which her pain substantially decreased for a year and a half before returning. She has divorced her second husband and is now working. She also has limited her sexual activities and engages in masturbation, through which she has discovered orgasm.

\section{Case 2}

This subject is a white woman in her late 40 s who has been physically and sexually abused by her husband for about ten years. She is not financially independent and states this as her reason for staying in the relationship. Her husband beats her once or twice a year when he is intoxicated. She accepts this as her lot in life. Between beatings, he is sexually demanding, insisting on oral ejaculation and anal penetration, practices that she considers unhygienic. Although this activity was also "toler- ated," it always resulted in her complaint of a "vaginal infection," for which she has seen many family practitioners as well as gynecologists; findings of all examinations, smears, and cultures have proved negative. The subject has been treated with almost every agent that is acceptable for insertion into the vagina, all to no avail. Having recently found out about the infidelity of her husband, she is now more convinced than ever that she has an infection, and she pursues physicians for treatment, totally unaware of the relationship between her marital relations and associated abuse and her imaginary infections. She finally has accepted therapy and is making some improvement.

\section{Case 3}

This is a nulliparous woman in her early 30 s who was raped by a relative when she was in her late 20 s. Prior to the rape, there had been no history of assault or abuse. After the assault, she had profuse bleeding during her menstrual periods, which required a curettage and pelvic examination under anesthesia. No abnormalities were detected during the examination, and the endometrium was reported to be secretory. She continued to have an abnormal profuse menstrual flow for six months, then had amenorrhea for five months, and again returned to profuse menstrual flow.

Hysteroscopy and curettage were performed on two occasions. On the first, the endometrium was found to be normal proliferative; on the second, normal secretory. Laparoscopy also was performed and revealed no abnormalities. The patient was managed with high doses of progestogens with only fair response, best noted as unpredictable. She desires marriage and children but also discusses having a hysterectomy, believing that the assault hurt her female organs. She remains sexually active but tends to have postcoital bleeding at any phase of the menstrual cycle. Current treatment with norethindrone aceiate has not affected this pattern. She reports experiencing few orgasms during intercourse or masturbation. This woman has been urged to seek therapy but has not yet accepted this form of management. The norethindrone acetate, at a dosage of 20 to $30 \mathrm{mg}$ per day, causes emotional reactions. When the bleeding is very profuse, this woman relives the assault episode in dreams.

\section{Conclusions}

Rape or physical abuse is an experience that produces a high degree of anxiety. In our sample, as in those of other studies, ${ }^{13}$ it is not surprising to find that after an assault the victim focuses her fears on her sexual organs/system, inasmuch it is these that have been violated. Anxiety is a sympathicotonic manifestation and as such disturbs the parasympathetic-sympathetic staircase that produces the joy of sex and proper sexual function. Our findings are comparable with those of other reports; 


\section{Table 4 \\ Conclusions}

- Women with history of abuse/assault

Show more sexual dysfunction

Show significantly more pelvic pain and surgery

- Women with chronic unexplained pain

Should have past reviewed for assault

Should have current life studied for abuse

Surgery should be approached with caution as

relief is short-lived

- Women with chronic vaginitis

Should be studied for abuse/assault

- All women with sexual dysfunction, particularly with gynecologic symptoms

Should be evaluated for abuse/assault

the variations in percentages may be accounted for by the difficulties mentioned in sampling.

The finding that $61 \%$ of the raped and abused women manifested some sexual dysfunction over a period of two to four years after the assault and the inference based on these findings that the dysfunction is a chronic one, leads me to the conclusion that for all women with a history of sexual dysfunction the possibility of sexual abuse or partner-intimacy abuse should be explored.

The sexual system uses the parasympatheticsympathetic "explosion" to act out the joys and pleasures of the sexual act. This affects the hypothalamic areas of the brain and thus the endocrinology and physiology of the reproductive system. As we have seen, the fear and lack of desire arising from the sexual or physical abuse do not alter the gynecologic function as much as the more intense physiologic states of arousal and orgasm. We find far more gynecologic pain and abnormal bleeding in rape victims and in abused women; in rape victims, we find an apprehension about infection, which will manifest itself as pelvic pain, leukorrhea, dyspareunia, and vaginismus. These physical manifestations are caused by changes in the autonomic balance for arousal-orgasm, with attendant changes in the myotonia-phenomena. ${ }^{18}$ The history of women with chronic pelvic pain, leukorrhea, or abnormal bleeding should be investigated for abuse-past or present.

Although they are based on observations, these conclusions should prompt physicians to be vigilant for the abused woman. Table 4 summarizes the conclusions.

\section{Summary}

The nature of the sexual dysfunctions that result from rape and abuse may vary, but this study suggests that the dysfunctions become chronic. Time does not heal the fears or the changes in desire, arousal, or orgasmic patterns that ensue. Gynecologists and other practitioners who treat women should remain aware that assaults alter a woman's affective life as well as her gynecologic-physiologic life. It is further concluded that pain that is related to such events as rape or abuse may not be permanently removed by a surgical procedure if it is the sole criterion for the surgery. This is a relevant consideration in this litigious age.

\footnotetext{
1. Burgess AW, Holmstrom LL: Rape: Victims of Crisis. Bowie, Md, Robert J. Brady, 1974.

2. Burgess AW, Holmstrom LL: Rape trauma syndrome. Am J Psychiatry 1974:131:981-986.
}

3. Peters JJ: Social psychiatric study of victims reporting rape. Paper presented at the annual meeting of the American Psychiatric Association, Anaheim, Calif, May 1975.

4. State of California Criminal Justice Office: Rape Victimization Study. San Francisco, Queens Bench Foundation, June 1975.

5. Sutherland S, Scherl D: Patterns of response among victims of rape. Am J Orthopsychiatry 1970;40:503-511.

6. Becker JV, Skinner LJ, Abel GG, et al: Incidence and types of sexual dysfunctions in rape and incest victims. $J$ Sex Marital Ther, Spring 1982;8:65-74

7. Becker JV, Skinner LJ, Abel GG, et al: Sexual problems of sexual assault survivors. Women Health 1984;9(4):5-20.

8. Becker JV, Skinner LJ, Abel GG, et al: Level of postassault sexual functioning in rape and incest victims. Arch Sexual Behav 1986;15:37. 49.

9. Chapman JD: Sexuality-The mature childbearing years and the effect of gynecologic surgery. JAOA 1979;78:509-514.

10. Bart PB: Rape doesn't end with a kiss. Unpublished manuscript. Chicago, Abraham Lincoln School of Medicine, University of Illinois, Department of Psychiatry, 1975.

11. McGuire LS, Wagner NN: Sexual dysfunction in women who were molested as children. $J$ Sex Marital Ther 1978;4:11-15.

12. Burgess AW, Holmstrom LL: Rape: Sexual description and recovery. Am J Orthopsychiatry 1979;49:648-657.

13. Feldman-Summers S, Gordon PE, Meagher JR: The impact of rape on sexual satisfaction. $J$ Abnorm Psychol 1979;88:101-105.

14. Kistner R: Gynecology - Principles and Practice, ed 4. Chicago, Year Book Medical Publishers, Inc, 1986.

15. Masters WH, Johnson VE: Sex and Human Loving. Boston, Little, Brown \& $\mathrm{Co}, 1980$

16. Hite S: The Hite Report. New York, Macmillan Publishing Co, Inc, 1976.

17. Chapman JD: The Sexual Equation. New York, Philosophical Library, Inc, 1977.

18. Masters WH, Johnson VE: Human Sexual Response. Boston, Little, Brown \& Co, 1966

Reprint requests to Dr Chapman, Box 340, Madison, OH 44057 0340 . 